\title{
Isotropic non-contrast whole-heart lumen only coronary MRA using local re-inversion and 2D-SENSE at 3 Tesla
}

\author{
Harsh K Agarwal ${ }^{1 *}$, Jing Yu', Micheal Schär ${ }^{2}$, Allison Hays ${ }^{1}$, Robert G Weiss ${ }^{1}$, Matthias Stuber ${ }^{1}$ \\ From 2011 SCMR/Euro CMR Joint Scientific Sessions \\ Nice, France. 3-6 February 2011
}

\section{Introduction}

Double-inversion recovery MRI with a cylindrical reinversion prepulse has been presented for selective visualization of the coronaries [1]. Local re-inversion (LoReIn [1]) labels the blood in the ascending aorta and $\mathrm{LV}$, and acquires images after a labeling delay providing coronary MRA(cMRA) of the blood flow with excellent suppression of myocardial signal. LoReIn was now implemented and tested for whole-heart cMRA [2] at high magnetic field strength.

\section{Purpose}

To develop a whole-heart cMRA of the blood flow during a labeling delay with complete suppression of myocardial signal at $3 \mathrm{~T}$.

\section{Methods}

Whole-heart cMRAs were obtained in four healthy volunteers during free breathing on a commercial Phillips Achieva 3T MR scanner using a 32-channel cardiac coil. A $3 \mathrm{D}$ gradient-echo sequence (TR/TE $=3.3 \mathrm{~ms} / 1.09 \mathrm{~ms} ; \alpha=20^{\circ}$; acquisition window $=107.5 \mathrm{~ms} ; \mathrm{FOV}=272 \mathrm{mmx} 232 \mathrm{mmx}$ $120 \mathrm{~mm}$; voxel size $=1.3 \mathrm{~mm} \times 1.3 \mathrm{~mm} \times 1.3 \mathrm{~mm}$; SENSE $=2$ in foot-head direction; SPIR fat saturation) was acquired twice first with T2-preparation [2,3] and then with LoReIn preparation to generate blood-myocardium contrast. A $25 \mathrm{~mm}$ radius $2 \mathrm{D}$ cylindrical shaped labeling pulse through the ascending aorta was applied after the R-wave and images were acquired after a labeling delay [4] to suppress the myocardial $(\mathrm{T} 1=1200 \mathrm{~ms})$ signal at $3 \mathrm{~T}$. Imaging every other heart beat enabled a labeling delay of $550-650 \mathrm{~ms}$ to capture the two peaks of pulsatile blood flow [5] and

\footnotetext{
'Johns Hopkins University, Baltimore, MD, USA

Full list of author information is available at the end of the article
}

image acquisition during mid-diastole. Scan time(320 heart beats) was kept constant by changing the fold-over direction and using an additional SENSE factor of 2 in right-left direction. SNR of blood, blood-myocardium $\mathrm{CNR}$, and vessel length were statistically compared using Student's t-test for significance below p-value of 0.05 .

\section{Results}

All scans were successfully completed with both techniques. An example reformatted RCA and LAD in Figure 1

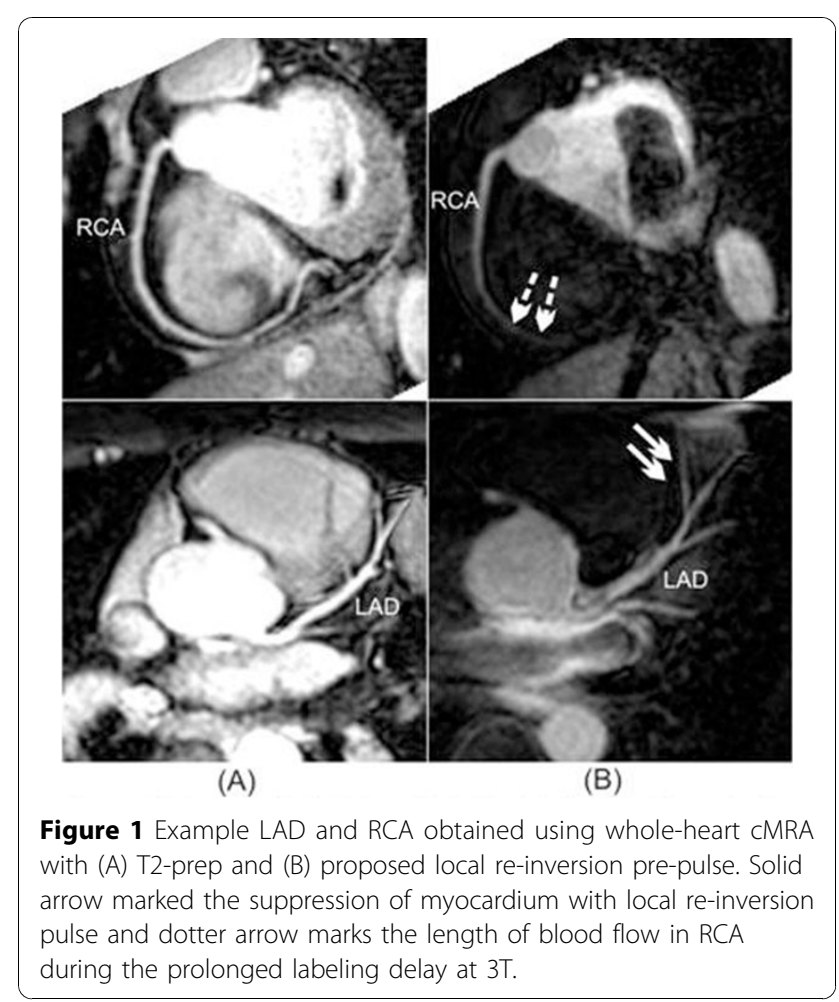


Table 1 Quantitative comparison of cMRA obtained using T2-Prepared and local re-inversion pre-pulse

\begin{tabular}{lll}
\hline & $\begin{array}{l}\text { Whole-heart } \\
\text { T2-Prepared cMRA }\end{array}$ & $\begin{array}{l}\text { Whole-heart local } \\
\text { re-inversion prepared cMRA }\end{array}$ \\
\hline SNR blood & $116 \pm 51$ & $121 \pm 41$ \\
CNR blood and & $63 \pm 35$ & $121 \pm 41^{*}$ \\
myocardium & & \\
RCA length (mm) & $116.9 \pm 13.8$ & $55.6 \pm 12.2^{*}$ \\
LCX length (mm) & $57.1 \pm 12.1$ & $53.6 \pm 7.0$ \\
LAD length (mm) & $57.0 \pm 20.1$ & $50.7 \pm 11.2$ \\
\hline
\end{tabular}

${ }^{*} \mathrm{p}<0.05$ using Student's t-test.

shows the suppression of myocardium with LoReIn and the extent of blood flow into the RCA during the labeling delay. The quantitative results are listed in Table 1. Visible vessel length of LAD and LCx is similar between the two scans, however, a longer RCA is visualized for T2-prepared scan which is independent of the in-flow of blood. SNR of blood is similar for both techniques, however, the CNR between blood and myocardium is significantly higher with LoReIn.

\section{Conclusions}

2D-SENSE accelerated isotropic whole-heart cMRA of the blood flow during a labeling delay with suppressed fat and myocardium has been successfully developed and applied at 3T for visualizing continuous segments of major coronary arteries.

\section{Acknowledgements}

Grant Sponsor : NIH/NHLBI (ROI-HL084186) and Reynolds Foundation

\section{Author details}

'Johns Hopkins University, Baltimore, MD, USA. ${ }^{2}$ Philips Healthcare,

Cleveland, $\mathrm{OH}$, USA.

Published: 2 February 2011

\section{References}

1. Katoh M, et al: JMRI 2008, 27(4):913-7.

2. Weber OM, et al: MRM 2003, 50(6):1223-8.

3. Nezafat $R$, et al: MRM 2006, 55(4):858-64

4. Fleckenstein JL, et al: Radiology 1991, 179(2):499-504.

5. Brandt A, et al: JMRI 2010, 31(5):1215-23.

doi:10.1186/1532-429X-13-S1-026

Cite this article as: Agarwal et al.: Isotropic non-contrast whole-heart

lumen only coronary MRA using local re-inversion and 2D-SENSE at 3

Tesla. Journal of Cardiovascular Magnetic Resonance 2011 13(Suppl 1):O26.
Submit your next manuscript to BioMed Central and take full advantage of:

- Convenient online submission

- Thorough peer review

- No space constraints or color figure charges

- Immediate publication on acceptance

- Inclusion in PubMed, CAS, Scopus and Google Scholar

- Research which is freely available for redistribution

Submit your manuscript at www.biomedcentral.com/submit 